\title{
Socio-Economic Characteristics Influencing Pastoralists' Risk Avers Attribute Using Ordered Probit Model
}

\author{
Mohammed Jemaneh Seid* Nassir Hammedu Nassir \\ Afar Pastoral and Agro-Pastoral Research Institute, Socio-Economics, Extension and Gender Research \\ P.O.Box 16, Semera, Ethiopia
}

Supported by the Regional capital project for Afar Pastoral and Agro-Pastoral Research Institute (APARI). Abstract

This research used data from 210 pastoralists and agro-pastoralists that were randomly selected from three Weredas of Afar region by following a multi-stage sampling procedure. Data were analysed using both descriptive statistical methods and econometric model. First, to assess the factors influencing the risk perception of the household regarding environment, index was developed in a Likert scale fashion and regressed to the hypothesized explanatory variables using order probit regression model. The odds ratio and marginal effects of each outcome variables were computed after estimation. The latent variable pastoralist exposure to environmental risks is increasing with age of household and education level increase. The results may suggest that the influence of significant socio-economic characteristics must be well revised to decrease the risky life of pastoralists in the study area.

Keywords: Afar pastoralists, risk perception, order probit

DOI: $10.7176 / \mathrm{JESD} / 11-5-07$

Publication date:March $31^{\text {st }} 2020$

\section{Introduction}

Risk is assumed as an inseparable event in every day today activities. Most humans engage in some kind of dangerous events every day and this ubiquity has prompted a substantial effort within researchers to understand how people understand risk. Everyone is seeking to manage risk, and they are all guessing because if they knew for certain, they would not be dealing with risk (Adams, 1995). In other words, in any definite situation, an adverse outcome may or may not occur and causative factors skew the probabilities of diverse outcomes (Graham and Rhomberg, 1996).

Risk has been defined in a number of ways, but is often seen as the likelihood that an individual will experience the effect of danger (Short Jr, 1984). Wherever it is discussed, it seems to be a consensus about essence of risk as being consisting of the probability of an adverse event and the magnitude of its consequences (Rayner and Cantor, 1987). This definition may be adequate to define risk of engineering-type calculations, but quite misleading at a broader, more intractable, level of large-scale societal risk management. All risk concepts have one element in common; a distinction between reality and possibility. A discussion around the uncertainty of a situation has prevailed and Rosa (2003: 56) defined risk as "a situation or an event where something of human value (including humans themselves) is at stake and where the outcome is uncertain". Hence, uncertainty is closely related to risk and in many theories of behaviour, psychological uncertainty is assumed to be an important mediator of human responses in situations with unknown outcomes. Uncertainty is a psychological construct. It "exists only in the mind; if a person's knowledge was complete, that person would have no uncertainty" (Windschitl and Wells, 1996).

According to the world encyclopaedia, risk perception is the subjective judgment that people make about the characteristics and severity of a risk. The phrase is most commonly used in reference to natural hazards and threats to the environment or health, such as nuclear power. Several theories have been proposed to explain why different people make different estimates of the dangerousness of risks. Three major families of theory have been developed: psychology approaches (heuristics and cognitive), anthropology/sociology approaches (cultural theory) and interdisciplinary approaches (social amplification of risk framework). Thus, the study of risk perception arose out of the observation that experts and lay people often disagreed about how risky various technologies and natural hazards were.

Pastoralism, by WISP (2007) definition, is the finely-honed symbiotic relationship between local ecology, domesticated livestock and people in resource-scarce, climatically marginal and highly variable conditions. It represents a complex form of natural resource management, involving a continuous ecological balance between pastures, livestock and people.

On the other hand, Philip Thornton and et al (2007) emphasize about local knowledge of risk as: Another critical need is the development of collaborative learning processes to support the adaptation of livestock systems to better cope with the impacts of climate change. Research cannot hope to contribute to improving adaptive capacity without a comprehensive understanding of the context in which decisions about adaptation are made and of the capacity of decision makers to change. Farmers already have a wealth of indigenous knowledge on how to 
deal with climate variability and risk. However, there is still a need to assess these adaptation options in relation to reducing vulnerability of humans and ecosystems, particularly options associated with livestock, with the object of maintaining or increasing food security, incomes and resilience while maintaining key ecosystem functions. Such assessment needs to be done in conjunction with well-targeted capacity building efforts to help farmers deal with changes in their systems that go beyond what they have experienced in the past. Thus, this study highlights the risk perception and risk averse attribute of Afar pastoralist using empirical analysis.

The main objective of this research was to assess the socio-economic factors affecting the risk averse attribute of pastoralist related to their natural environment, and how these in turn influence their livelihood. Specifically, it was aimed to identify a range of risk perception among pastoralist and their way of coping systems to sustain their livelihood in the study area

\section{Research Methodology}

\subsection{Description of the study area}

The research was undertaken in Afar region of Ethiopia. The Afar national regional state is located in the northeast part of the country. It is geographically located between $39^{\circ} 34^{\prime}$ and $42^{\circ} 28^{\prime}$ East Longitude and $8^{0} 49^{\prime}$ and $14^{0} 30^{\prime}$ North Latitude (Afar atlas, 2006). Afar region covers an area of 94,760 square kilometers. The whole of the territory is semi-arid or arid where the altitude varies from 126 meters below sea level to just less than 1,500 meters above sea level. The vegetation found in the northern part is thorny species of shrubs and acacia while further in the south, steppe is dominant vegetation pattern (UNDP, 2000).

The research design followed a three-stage sampling procedure. In the first stage, Awra, Assayita, and Amibara Weredas' from the three zone of the region were purposively selected. In the second stage, 10 kebeles were randomly selected for undertaking the study. Both random and purposive sampling procedure were employed in the selection of the sample pastoralists and agro-pastoralists from the study area. And a total of 210 pastoralists and agro-pastoralists were selected based on population size.

In this study, both primary and secondary data were used. The data had both Quantitative and Qualitative nature. Primary data were collected from sampled respondents through pre-tested structured questionnaire and interview. Additionally, written documents including those from agricultural and pastoral rural development bureau and recent research works about the study area were used as secondary data.

\subsection{Data Analysis}

Measuring risk: as literatures indicate, the simplest studies of risk perceptions focus on how well people understand objectively measurable risks. This allows researchers to see whether factual information is accurately understood. For instance, Buhler (2003) asked respondents whether sexual intercourse was a way of becoming infected with HIV/AIDS. This approach helps to identify information gaps, but it does not account for the possibility that people may see certain risks as unimportant if they believe that their behavior can mitigate their personal risk exposure. On the other hand, Mohammed (2012) used a multinomial logit utility model to identify pastoralist perception regarding invasive species risk.

A further way to measure subjective risk perceptions is to ask people to rank different risks. This does not give an intensity measure, but it does provide an ordinal measure that is important when one needs to prioritize the allocation of scarce resources, as is chronically the case considering development alternatives in the ASALs of Africa.

\subsubsection{Descriptive analysis}

The collected data were analyzed using different statistical tools. The quantitative data were presented in tabular forms (mean, frequency, standard deviation) while the qualitative one incorporated during description to support the quantitative data.

\subsubsection{Econometric Analysis}

Ordered Probit Regression Model

To develop a probabilistic model of market/environmental risk an ordered probit regression model is formulated, which is adjusted by using perceived risk data. Intensity of the risk can be expressed by a scale categorizing risk into three levels. The regression model is formulated to suit the categorical response variable.

Model formulation

Since the risk levels used in the scale are subjective but ordered in nature, an ordered categorical analysis will be most appropriate to treat such data. Two possible regression models may be employed: the ordered probit model. This model differs from ordered logit model in the assumption of the distributions of regression errors. The ordered probit model is selected for this study though the choice matters little as both models produce very similar results. The ordered probit model is usually formulated as a latent (i.e., unobserved) variable framework. The structural model specification is:

$$
\boldsymbol{Y}_{i}^{*}=\boldsymbol{\beta} \mathbf{X}_{\mathbf{i}}+\varepsilon_{\mathbf{i}}
$$

where $y_{i} *$ is a continuous latent variable measuring perceived market/environmental risk for the $i^{\text {th }}$ set of $X ; X_{i}$ is 
the vector of independent variables; $\beta$ is the vector of regression coefficients; $\boldsymbol{\varepsilon}_{\mathbf{i}}$ is the random error term $\sim \mathrm{N}(0,1)$. The measurement model, in which the latent variable $y_{i} *$ is mapped on to an observed ordinal variable $y$, is specified as: $y_{i}=\mathrm{m}$ if $\tau_{\mathrm{m}-1} \leq \boldsymbol{y}_{i} *<\tau_{\mathrm{m}}:$ for $\mathrm{m}=1$ to $J$

Where $\mathrm{J}$ is number of ordinal categories in $y$ and the threshold values $(\tau)$ are unknown parameters describing the boundaries of risk levels.

Therefore, the observed discrete risk levels are tied to the continuous latent variable as follows:

1 if $-\infty \leq \boldsymbol{y}^{*}<\tau[\mathrm{V} /$ High Risk (VHR)]

2 if $\tau_{1} \leq \boldsymbol{y}^{*}<\tau_{2}$ [High Risk (HR)]

$\boldsymbol{y}_{\boldsymbol{i}}=3$ if $\tau_{2} \leq \boldsymbol{y}^{*}<\tau_{3}$ [Moderate Risk (MR)]

4 if $\tau_{3} \leq y^{*}<\tau_{4}$ [Low Risk (LR)]

5 if $\tau_{4} \leq y^{*}<\infty$ [Safe]

Where; the threshold values $\tau_{1}, \tau_{2}, \tau_{3}$ and $\tau_{4}$ are unknown parameters to be estimated. Based on the normality assumption of the error term, the probability of risk level $m$ for given $\mathbf{X}_{\mathbf{i}}$ can be predicted as:

$$
\hat{P} r\left(y=m \mid X_{i}\right)=F\left(\hat{\tau}_{m}-\hat{\beta} X_{i}\right)-F\left(\hat{\tau}_{m-1}-\hat{\beta} X_{i}\right) ; \sum_{m=1}^{J} \hat{P} r\left(y=m \mid X_{i}\right)=1
$$

Where; $F$ is the cumulative distribution function for $\boldsymbol{\varepsilon}$.

Once the probabilities of each risk level are predicted from the model estimates, associated market/environmental risks can be computed. To do so, risk scores $\left(R S_{m}\right)$ are assigned to each risk level based on the thresholds. The $R S_{m}$ represents the probability of market/environmental for risk level $m$. Using the proposed risk scale, risk scores for VHR and Safe levels are assigned values of 1 and 0 respectively. The VHR level refers to interactions when market/environmental risk become higher and cannot be avoided, which represents the probability of risk as 1 . On the other hand, where no action is required under the Safe level, the probability of risk is zero. As seen from equation (3), the Safe level exists if $y^{*} \geq \tau_{4}$. The $\tau$ values may be normalized to a probability value with the range $[0,1]$.

The environmental risk for the given $\mathbf{X}_{\mathbf{i}}$ can then be computed as:

$$
P_{r} \mid X_{i}=\sum_{m=1}^{J} R S_{m} \times \hat{P} r\left(y=m \mid X_{i}\right) ; 0 \leq P_{r} \leq 1
$$

\section{Result and Discussion}

To achieve the intended objectives, the researcher employed both descriptive and econometric analysis. First, to assess the factors influencing the risk perception of the household regarding their environment, index was developed in a Likert scale fashion and regressed to the hypothesized explanatory variables using order probit regression model. The odds ratio and marginal effects of each outcome variables were computed after order probit regression model estimation.

\subsection{Socio-Economic Characteristic}

The survey findings in Table 1 showed that household market risk perception accounted $20.5 \%$ low, $50 \%$ moderate and $29.5 \%$ high market risks availed in the study area. Likewise, regarding perceived environmental risks, households accounted $24.8 \%, 48.1 \%$, and $27.1 \%$ in the low, moderate and high-risk category respectively. The $X^{2}$ value of both categorical variables were significant by less than $1 \%$ significant level. Moreover, A significant difference was observed with past and present perception on the kind of risks arisen and between each kebeles. The area was repeatedly threatened by drought and natural calamity. Access for credit, appropriate technology instrument, improved seed and fertilizers were not available for the pastoralists to combat the hardship. With low infra structure, the above problems worsen pastoralists living. Pastoralists practice different coping mechanisms like migration, diversification, loan and aid. Thus, livelihood diversification, distress-push diversification, seems their coping strategy for the prevailed risks in the area.

Here in the descriptive analysis part, as the survey results in Table 2 display that mean of household age was 36.89 , the average household family size was 7.09 , pastoralists travel around $12.76 \mathrm{~km}$ to sell their product and buy necessary goods near to the available market places, tropical livestock unit accounted 32.19 , they hold averagely 1.24 hectare of farming land, and they earned nearly 15.11 quintals per year, they had 3.97 years of farming experience, according to respondents averagely they lost 24.57 livestock in the previous season. It is a great lose even if it needed other cross-checking data before any conclusion made. The author of this research recommends further studies regarding livestock epidemics, number and types of dead livestock.

Likewise, results of categorical variables indicate that, the sample respondents constitute 53 (25.24\%) female and $157(74.76 \%)$ male household heads. With regard to education status, $153(72.86 \%)$ respondents were illiterate and $57(27.14 \%)$ respondents were literate. With respect to household access to veterinary service, about 29 $(13.81 \%)$ households got animal health extension service from government institutions, only $1(0.48 \%)$ household got from non- governmental organization, and around $20(9.52 \%)$ household got the services from other entities which are not mentioned here, but the majority of $160(76.19 \%)$ households got the service from private agency by their own cost $\left(X^{2}=178.64, \mathrm{p}<0.01\right)$. This could give us an indication that even if extension service was very 
important, less emphasis was given by the concerned bodies. As a result, many pastoralists were challenged to incur the expenditure to get the service.

\subsection{Market access and Environmental risks}

The area is familiar by the prevalence of climate change; it has higher mean value (4.08). Contrarily, environmental impact of projects (like wastage of factory, river or air pollution) became lesser (2.33). Lack of conducive environment for employee and lack of skilled worker are moderate. The problem arise due to these skilled workers were not working what they were expected to work. That means, there are idle human resources.

\subsection{Ordered Probit Regression of Environmental Risk Perception}

The latent variable pastoralist exposure to environmental risks (ecrisk) become higher with age of household, education level, training access, the experience of household to educate his/her child increase. The interpretation might be various based on the context. However, environmental risk (ecrisk) is decreasing with household sex, family size, TLU, crop residue, drought occurrence and cash deposit in bank.

\section{Conclusion and Policy Recommendation}

\subsection{Conclusion}

Based on the pastoralist response, the indigenous trees and animal feed become diminishing from time to time, and the range land degradation increase for the last few years. Consequently, these aggravate the risky life of pastoralist to live. The damages were multi-sectored and interdependent. Once the indigenous species get threatened, pastoralists were unable to diagnose livestock traditionally when diseases and epidemic occurred in the area. Survey result displayed that the majority of variables like; frequent livestock epidemic, disease transmission to human, and traditional disease treatment may confirm the risky live of pastoralists. Having understood this context, access to animal health extension service was the other challenge for combating the existed problems.

The order probit model estimation indicated that the latent variable pastoralist exposure to environmental risks (ecrisk) become higher with age of household, education level, training access, the experience of household to educate his/her child increase. The interpretation might be various based on the context. However, environmental risk (ecrisk) is decreasing with household sex, family size, TLU, crop residue, and cash deposit in bank.

\subsection{Policy Recommendation}

Based on the survey results showed in the former section, the following recommendations are forwarded

The variable training has a positive sign on dependent variables. So that, trainers have to revise the issue and contents of training, and it must be based on pastoralist demand and on target.

As age increases household exposure to environmental risks become higher and higher. Therefore, concerned body and policy makers must take in to consideration this negative correlation.

The variables sex, family size, TLU, land size, experience in farming, and kind of grazing, use of crop residue, and saving cash in bank decrease the exposure of pastoralists being at the higher market and environmental risks. These socio-economic characteristics are imperative for decision makers and other stakeholders to get-out pastoralists from the frequent risks in the area.

Lack of favorable work environment for employee (career satisfaction) and lack of skilled worker were the biggest challenges in the area. Even if there have been significant skilled workers in the region, the problem arise these skilled workers were not working what they are expected to work due to employees are not well empowered to contribute their part. It needs urgent investigation for achieving the transformation and millennium development goal of the region and country. However, concluding that the regional sector bureau has not been utilizing the available human capital and not gotten what are expected from these skilled workers is straightforward.

The interpretation might be various based on the context. However, further empirical research concerning this issue in different situations and context should be made before proposition of more widely applicable statements and recommendations forwarded.

\section{References}

Adams, J. (1995). Risk. London: UCL Press. af Wåhlberg, A. E. (2001). The theoretical features of some current approaches to risk perception. Journal of Risk Research., 237, 250.

Graham, J. D., and Rhomberg, L. (1996). How risks are identified and assessed. ANNALS, 545, 15-24.

Kouame, E.B.H. and Komenan, A.N., (2012). Risk Preferences And Demand For Insurance Under Price Uncertainty: An Experimental Approach For Cocoa Farmers In Côte D'ivoire. Research Paper No. 13, International Labor Union, Geneva.

Mohammed Jemaneh. (2012). Household Perception about Prosopis Juliflora and Its Effect on Pastoral Livelihood 
Diversification Strategy, International Journal of Agricultural Science and Research (IJASR), 2(3), 21-51.

Short Jr, J. F. (1984). The social fabric of risk: towards the social transformation of risk analysis. Am. Sociol. Rev., 49(Dec.), 711-725.

Rayner, S., and Cantor, R. (1987). How fair is safe enough? The cultural approach to societal technology choice. Risk Anal, 7, 3-9.

Rosa, E. A. ( 2003). The logical structure of the social amplification of risk framework (SARF): Metatheoretical foundation and policy implications. In N. K. Pidgeon, R.E.and Slovic, P (Ed.), The social amplification of risk. (pp. 47-79). Cambridge: Cambridge University Press.

Windschitl, P. D., and Wells, G. L. (1996). Measuring psychological uncertainty: verbal versus numeric methods. Journal of Experimental Psychology. Applied, 2(4), 343-364.

Loewenstein, G. F., Weber, E. U., Hsee, C. K., and Welch, N. (2001). Risk as Feelings. Psychological Bulletin, 127(2), 267-286.

Kouabenan, D. R. (2002). Occupation, driving experience, and risk and accident perception. Journal of Risk Research, 5(1), 49-68.

Kraus, N. N., and Slovic, P. (1988). Taxonomic analysis of perceived risk: modeling individual and group perseptions. Risk Analysis, 8, 435-455

Table 1: household perceived risks regarding market and natural resource

\begin{tabular}{lllll}
\hline Variables & & Frequency & Sub table N \% & $\boldsymbol{X}^{2}$ - test \\
\hline \multirow{3}{*}{ market risk } & low & 43 & $20.5 \%$ & $169.351^{* * *}$ \\
& moderate & 105 & $50.0 \%$ & \\
\hline \multirow{3}{*}{ environmental risk } & high & 62 & $29.5 \%$ & $170.356^{* * *}$ \\
& low & 52 & $24.8 \%$ & \\
& moderate & 101 & $48.1 \%$ & \\
\hline
\end{tabular}

Table 2: Household Characteristics (Continuous Variables)

\begin{tabular}{llll}
\hline \multirow{2}{*}{ Variables } & \multicolumn{2}{c}{ Total observation } \\
\cline { 2 - 4 } & $\overline{\mathbf{X}}$ & SD & t-test \\
\hline Household Age & 36.89 & 14.02 & $37.85^{* * *}$ \\
Family size & 7.09 & 3.44 & $29.65^{* * *}$ \\
Market distance & 12.76 & 8.2 & $22.37^{* * *}$ \\
TLU & 32.19 & 33.34 & $13.89^{* * *}$ \\
Farming land in hectare & 1.24 & 1.34 & $13.29^{* * *}$ \\
Farming income & 15.11 & 18.7 & $11.62^{* * *}$ \\
Farming experience & 3.97 & 6.27 & $9.11^{* * *}$ \\
Number of dead animals & 24.57 & 20.51 & $17.23^{* * *}$ \\
\hline
\end{tabular}

Source: Survey data analysis

Note; $* * *$ and $* * *$ indicate significant at $10 \%, 5 \%$ and $1 \%$ probability level respectively 
Table 3: Household Characteristics (Categorical Variables)

\begin{tabular}{|c|c|c|c|c|}
\hline \multirow[t]{2}{*}{ Variables } & \multirow[t]{2}{*}{ Category } & \multicolumn{3}{|c|}{ Total Observation } \\
\hline & & Fre & $\%$ & $X^{2}$ test \\
\hline \multirow[t]{2}{*}{ HouseHold Sex } & female & 53 & 25.24 & $48.32 * * *$ \\
\hline & male & 157 & 74.76 & \\
\hline \multirow[t]{2}{*}{ education level } & illiterate & 153 & 72.86 & $22.49 * *$ \\
\hline & literate & 57 & 27.14 & \\
\hline \multirow[t]{2}{*}{ marital status } & single & 35 & 16.67 & $67.29 * * *$ \\
\hline & married & 175 & 83.33 & \\
\hline \multirow{2}{*}{ livelihood Household pursue } & pastoralism & 70 & 33.33 & $186.06^{* * *}$ \\
\hline & crop & 140 & 66.67 & \\
\hline \multirow[t]{2}{*}{ Training } & no & 162 & 77.14 & $15.47 *$ \\
\hline & yes & 48 & 22.86 & \\
\hline \multirow[t]{2}{*}{ occurrence of live epidemic } & no & 19 & 9.05 & $23.35 * *$ \\
\hline & yes & 191 & 90.95 & \\
\hline \multirow[t]{2}{*}{ Identifying symptom of disease } & no & 16 & 7.62 & $14.46^{* *}$ \\
\hline & yes & 194 & 92.38 & \\
\hline \multirow[t]{2}{*}{ transmition to human } & no & 121 & 57.62 & $75.61 * * *$ \\
\hline & yes & 89 & 42.38 & \\
\hline \multirow[t]{2}{*}{ traditional disease treatment } & no & 46 & 21.90 & $24.04 * *$ \\
\hline & yes & 164 & 78.09 & \\
\hline \multirow[t]{4}{*}{ Animal health extension. Service source } & Gov't institution & 29 & 13.81 & $178.64 * * *$ \\
\hline & Self & 160 & 76.19 & \\
\hline & NGOs & 1 & 0.48 & \\
\hline & other & 20 & 9.52 & \\
\hline
\end{tabular}

Source: Survey data analysis

Note; $* * *$ and $* * *$ indicate significant at $10 \%, 5 \%$ and $1 \%$ probability level respectively

Table 4: Ordered Probit Model of Risk Perception

\begin{tabular}{lll}
\hline Explanatory variables & Coef. & Std. Err. \\
\hline Age & $.0114125^{*}$ & .0073387 \\
Sex & $-.5879611^{* * *}$ & .2181547 \\
edu1 & $.3725967^{*}$ & .2095998 \\
Family size & $-.0976424^{* * *}$ & .0323839 \\
Training & .1516274 & .2185889 \\
TLU & $-.0045338^{*}$ & .0029322 \\
Land size & -.0806341 & .0798772 \\
Farming income & .0062122 & .0053358 \\
Experience in farming & .018932 & .0188757 \\
Feeding & -.1921007 & .2429722 \\
Crop residue & $-.9169043^{* * *}$ & .2416516 \\
Drought & $-.6889561^{*}$ & .3601119 \\
Tree planting & -.0390145 & .1957003 \\
Save cash in Bank & $-.8856789^{* * *}$ & .3119645 \\
Child education & $1.395883^{* * *}$ & .277245 \\
\hline & & \\
\hline /cut1 & -1.979501 & .5251691 \\
/cut2 & -.1919004 & .5126253 \\
\hline Log likelihood & -163.29812 & \\
Observation & 207 & \\
LR chi2(15) & 108.01 & \\
Prob> chi2 & 0.0000 & \\
Pseudo R2 & 0.248 & \\
\hline \hline
\end{tabular}

Source: Survey data and author's estimation

Note; $*, * *$ and $* * *$ indicate significant at $10 \%, 5 \%$ and $1 \%$ probability level respectively 